OPEN ACCESS

Edited by:

Qingxin Mu,

University of Washington,

United States

Reviewed by:

Guangbo Qu,

Research Center

for Eco-environmental Sciences

(CAS), China

Yanyan Liu,

Peking University, China

*Correspondence:

Bing Yan

drbingyan@yahoo.com

Gaoxing Su

sugaoxing@ntu.edu.cn

Specialty section: This article was submitted to

Nanobiotechnology,

a section of the journal Frontiers in Bioengineering and

Biotechnology

Received: 25 December 2019

Accepted: 03 March 2020

Published: 20 March 2020

Citation:

Yu Q, Zhao L, Guo C, Yan B and Su G (2020) Regulating Protein Corona Formation and Dynamic Protein Exchange by Controlling

Nanoparticle Hydrophobicity.

Front. Bioeng. Biotechnol. 8:210.

doi: 10.3389/fbioe.2020.00210

\section{Regulating Protein Corona Formation and Dynamic Protein Exchange by Controlling Nanoparticle Hydrophobicity}

\author{
Qianhui Yu', Linxia Zhao ${ }^{2}$, Congcong Guo', Bing Yan ${ }^{1,3 *}$ and Gaoxing Su2* \\ ${ }^{1}$ School of Environmental Science and Engineering, Shandong University, Qingdao, China, ${ }^{2}$ School of Pharmacy, Nantong \\ University, Nantong, China, ${ }^{3}$ Key Laboratory for Water Quality and Conservation of the Pearl River Delta, Institute \\ of Environmental Research at Greater Bay, Ministry of Education, Guangzhou University, Guangzhou, China
}

Physiochemical properties of engineered nanoparticles (NPS) play a vital role in nanobio interactions, which are critical for nanotoxicity and nanomedicine research. To understand the effects of NP hydrophobicity on the formation of the protein corona, we synthesized four gold NPs with a continuous change in hydrophobicity ranging from -2.6 to 2.4. Hydrophobic NPs adsorbed 2.1-fold proteins compared to hydrophilic ones. Proteins with small molecular weights $(<50 \mathrm{kDa})$ and negatively charge $(\mathrm{PI}<7)$ constituted the majority of the protein corona, especially for hydrophobic NPs. Moreover, proteins preferred binding to hydrophilic NPs (vitronectin and antithrombin III), hydrophobic NPs (serum albumin and hemoglobin fetal subunit beta), and medium hydrophobic NPs (talin 1 and prothrombin) were identified. Besides, proteins such as apolipoprotein bound to all NPs, did not show surface preference. We also found that there was a dynamic exchange between hard protein corona and solution proteins. Because of such dynamic exchanges, protein-bound NPs could expose their surface in biological systems. Hydrophilic NPs exhibited higher protein exchange rate than hydrophobic NPs. Above understandings have improved our capabilities to modulate protein corona formation by controlling surface chemistry of NPs. These will also help modulate nanotoxicity and develop better nanomedcines.

Keywords: surface chemistry, hydrophobicity, protein corona, nanoparticles, nano-bio interactions

\section{INTRODUCTION}

Engineered nanoparticles (NPs) with unique physical and chemical properties have been widely used in catalysis (Liu and Dai, 2016; Sharma et al., 2015), electronics (Liu et al., 2017; Wu, 2017), and biomedicine (Ramos et al., 2017; Ke et al., 2018). Until now, more than 3000 nanomaterial-based consumer products are on the market (Wei and Yan, 2016). These applications will increase the risk of human exposure to engineered NPs. To understand possible health issues of engineered NPs, it is necessary to clarify the basic interactions between NPs and physiological systems, blood, and biomolecules (Nel et al., 2009; Srivastava et al., 2015). Such understandings will significantly facilitate design of nanomedicine with well-defined pharmacokinetics and 
biodistribution (Walkey et al., 2012; Su et al., 2018). Therefore, understanding and tailoring the fundamental interactions between NPs and physiological systems has become a focus of nanotoxicity and nanomedicine research.

Physiological environments, such as blood, interstitial fluid, and cellular cytoplasm, contain complex protein mixtures. When engineered NPs enter such physiological environment, they spontaneously adsorb proteins to form protein corona (Cedervall et al., 2007a,b; Lundqvist et al., 2008; Ke et al., 2017). Protein corona may consist of tens or hundreds of proteins. They alter the physicochemical properties of NPs, such as size, zeta potential, morphology, and aggregation state (Gebauer et al., 2012; Su et al., 2012; Glancy et al., 2019; Marichal et al., 2019). At the same time, the protein corona also alters the interactions between NPs and biological systems and modulates the kinetics, transport, and reactivity of NPs (Monopoli et al., 2011; Lesniak et al., 2012; Walkey et al., 2012, 2014; Tenzer et al., 2013). For example, adsorbed proteins may act as opsonins, and dramatically enhanced the uptake of NPs by phagocytes (Walkey et al., 2012). Recent studies have shown that the synthetic identity of NPs plays an important role in determining the composition of the protein corona and the subsequent cellular interactions (Walkey et al., 2014; Caracciolo et al., 2015). Effects of size, shape, and surface chemistry of a NP on the protein corona formation were also studied (Johnston et al., 2017; Nienhaus and Nienhaus, 2019; Walkey et al., 2012; Su et al., 2016). Smaller NPs adsorb relatively more proteins compared to larger NPs due to a larger surface area in smaller NPs. Porous particles decreased the deposition of adsorbed proteins due to the size-exclusion effect (Clemments et al., 2015). Coating NPs with polyethylene glycol (PEG) or polysaccharides can minimize the protein adsorption (Walkey et al., 2012; Schöttler et al., 2016; Yahyaei et al., 2018). As the coating density increasing, less proteins are adsorbed. Although efforts have been made to minimize protein adsorption on NPs, systematic understanding of the relationships between the well-controlled NP's surface physiochemical properties and protein corona formation is relatively few.

The hydrophobic interaction is one of the most important interactions between molecules. It may be also so between NPs and proteins (Mahmoudi et al., 2011; Shemetov et al., 2012; Zhong et al., 2014). Foreign hydrophobic molecules or NPs are harmful to biological systems by disrupting cell membrane and protein folding. On the other hand, a certain degree of hydrophobicity was needed for drugs to cross cell membranes or biological barriers (Cunningham et al., 2018). Protein corona formation may change the hydrophobicity of NPs. Meanwhile, hydrophobicity of NPs may determine the nature of protein corona (Ashby et al., 2014; Vasti et al., 2016; Pareek et al., 2018). However, most reports were limited to NPs with a narrow distribution of $\log P$ range or surface ligands with different molecular structures making comparison difficult. In most cases, LogP values of NPs were not carefully characterized. In this work, we assembled NPs with a continuous change in surface hydrophobicity with identical size, shape and core material to investigate protein corona formation on these NPs. LogP values of these NPs were ranging from -2.6 to +2.4 , as measured by shaking-flask method. Due to the hydrophobic interactions, hydrophobic NPs adsorbed more than twice proteins of hydrophilic NPs. Proteomics analysis of protein corona was also carried out by nano-LC-MS/MS to identify proteins on NPs. Small and negatively charged proteins constituted the majority of adsorbed proteins. Moreover, adsorbed proteins were loosely associated to NPs and were dynamically exchanging with proteins in solution. The original physicochemical properties of NPs were mostly maintained in physiological environment. This study helps us understand protein corona formation in order to regulate corona in various applications.

\section{EXPERIMENTAL SECTION}

\section{MATERIALS}

Ligand A and B were prepared as we previously reported ( $\mathrm{Li}$ et al., 2015). Other chemicals were purchased from SigmaAldrich without purification. Glassware used in this study were immersed in aqua regia overnight and then washed with ultrapure water several times.

\section{Synthesis of Modified Gold NPs}

Hydrogen tetrachloroaurate (III) trihydrate $\left(\mathrm{HAuCl}_{4} \cdot 3 \mathrm{H}_{2} \mathrm{O}\right.$, $0.032 \mathrm{mmol}$ ) was added into $\mathrm{H}_{2} \mathrm{O}(0.625 \mathrm{~mL})$. A solution of mixture of ligand $\mathrm{A}$ and ligand $\mathrm{B}$ in different ratios in $\mathrm{DMF}$ $(0.625 \mathrm{~mL})$ was added to the mixture. After stirring for $30 \mathrm{~min}$, ice-cold $\mathrm{NaBH}_{4}$ solution $(0.131 \mathrm{mmol}, 0.5 \mathrm{~mL})$ was added to the mixture. The mixture solution turned red immediately and was vigorously stirred for $1 \mathrm{~h}$. After washing DMF and water five times, as-prepared NPs were dispersed in $5 \mathrm{~mL}$ of water and kept at $4^{\circ} \mathrm{C}$ until use. The ratios of ligand $\mathrm{A}$ and ligand $\mathrm{B}$ on gold NPs were measured by detaching the ligands using $\mathrm{I}_{2}$ and performing high-performance liquid chromatograph (Li et al., 2015). If the ratios were not the same as our design, ratios of ligand $A$ and ligand B were adjusted and measured once again.

\section{Characterization}

The morphologies of gold NPs were characterized by transmission electron microscopy (TEM) (JEM-1011, JEOL, operating at $100 \mathrm{kV}$ ). Hydrodynamic diameters and zeta potentials were characterized by dynamic light scattering (NanoBrook 90Plus Zeta, Brookheaven). Before measuring, these NPs should be sonicated several minutes to help disperse. The concentrations of each NP's stock solution were detected by inductively coupled plasma mass spectrometry (ICP-MS, Agilent).

\section{LogP Measurements}

First, octanol and water were mixed for $24 \mathrm{~h}$, and octanolsaturated water and water-saturated octanol were obtained. NPs $(0.1 \mathrm{mg})$ were diluted into octanol-saturated water $(2 \mathrm{~mL})$, and water-saturated octanol $(2 \mathrm{~mL})$ were added. The mixture was shaken for $24 \mathrm{~h}$ at room temperature and then stood still for $3 \mathrm{~h}$. NPs were separation from the two phases. After digesting with aqua regia, concentrations of NPs were measured by ICP-MS. The $\log \mathrm{P}$ values can be calculated according: $\log \mathrm{P}=\log \mathrm{C}(\mathrm{NP}$ in Octanol)/LogC (NP in Water). 


\section{Protein Adsorption}

After sonicating for several minutes, NPs $(0.1 \mathrm{mg})$ were added to PBS ( $1 \mathrm{~mL})$ containing $10 \%$ fetal bovine serum (FBS). The mixture was kept at $37^{\circ} \mathrm{C}$ water bath for $1 \mathrm{~h}$. Then, the mixture was centrifuged, the pellet was washed with PBS three times and NPs with protein corona were obtained.

\section{SDS-PAGE}

Nanoparticles with protein corona were dispersed into PBS. LDS loading buffer and 2-Mercaptoethanol were added and heating at boiling temperature for $5 \mathrm{~min}$ to release the bound proteins. After centrifugation, the supernatant was collected to run the sodium dodecyl sulfate-poly-(acrylamide gel electrophoresis) (SDSPAGE). At last, the gels were washed with water several times and stained with coomassie brilliant blue following the protocol.

\section{BCA Assays}

According to previous report (Su et al., 2018), the protein corona were recovered by sonicating the protein-bound NPs in extraction buffer (Tris-HCl buffer, $\mathrm{pH} 6.8,10 \%$ glycerol, and 4\% SDS) for several minutes. After centrifugation, the supernatant was collected and the protein concentration was measured by the BCA assay kit (Beyotime Biotechnology) according to manufacturer's protocol.

\section{Nano-LC-MS/MS}

For in solution digestion, a protein solution sample was first reduced by DTT and all Cysteine residues alkylated by iodoacetamide and cleaned by desalting columns or ethanol precipitation. The sample was then digested with sequencing grade modified trypsin (Promega) in the digestion buffer (ammonium bicarbonate $100 \mathrm{mM}, \mathrm{pH}$ 8.5). A dissolved peptide sample is then analyzed by a Nano-LC-ESI-MS/MS system.

Nano-LC-ESI-MS/MS analysis of a digested protein sample was carried out by a high-pressure liquid chromatography (HPLC) system (Agilent) with a $75 \mathrm{um}$ ID $8 \mathrm{~cm}$ in length in house packed reverse phase $\mathrm{C} 18$ capillary column. The particle size of the $\mathrm{C} 18$ column is $3 \mu \mathrm{M}$ and the pore size is $300 \AA$. The sample injection time was $20 \mathrm{~min}$. The HPLC Solvent A was $97.5 \%$ water, $2 \%$ acetonitrile, $0.5 \%$ formic acid. HPLC Solvent B is $9.5 \%$ water, $90 \%$ acetonitrile, and $0.5 \%$ formic acid. The gradation time was 60 min from $2 \%$ Solvent B to $90 \%$ solvent B, plus 20 min for sample loading, and $20 \mathrm{~min}$ for column washing. The column flow rate was around $800 \mathrm{~nL}$ per min after splitting. Typical sample injection volume is $3 \mu \mathrm{L}$.

\section{Protein Exchange Experiments}

Firstly, NPs $(0.5 \mathrm{mg})$ were mixed with $0.1 \mathrm{mg} / \mathrm{mL}$ FITC-labeled BSA solution. After shaking at $37^{\circ} \mathrm{C}$ for $1 \mathrm{~h}$ to form protein corona, the mixture was centrifuged at $20000 \mathrm{~g}\left(4^{\circ} \mathrm{C}, 1 \mathrm{~h}\right)$ and washed with PBS twice. Then, the supernatants were combined and the fluorescence intensity was measured. According to a calibration curve, amounts of unadsorbed FITC-labeled BSA was calculated. The total amount of adsorbed FITC-labeled BSA was calculated by subtracting the amount of unadsorbed FITClabeled BSA from the total amount of FITC-labeled BSA.
The NPs with fluorescence corona were then redispersed into $0.1 \mathrm{mg} / \mathrm{mL}$ non-labeled BSA solution. At different time points, a fraction of the solutions was centrifuged and the fluorescence intensity of the supernatant was determined. According to a calibration curve, amounts of exchanged FITC-labeled BSA were determined. The exchange rate was calculated by dividing the amount of exchanged FITC-labeled BSA with the amount of adsorbed FITC-labeled BSA.

\section{RESULTS AND DISCUSSION}

\section{Synthesis and Characterization of Nanoparticles With a Continuous Change in Hydrophobicity}

A NP array (NP01 NP04) with a continuous change in hydrophobicity was synthesized and their chemical structures were shown in Figure 1A. Two ligands were used: hydrophilic ligand A with a tri-ethylene glycol, and hydrophobic ligand $B$ with an undecane (Figure 1B). During the reduction of gold, ligands were attached in situ to gold NP surface through formation of $\mathrm{Au}-\mathrm{S}$ bond. By redundantly adjusting the ratios of ligands $\mathrm{A}$ and $\mathrm{B}$ in the reaction solution, NPs coated with various ratios of ligand $\mathrm{A}$ and $\mathrm{B}$ (such as $30 \%$ or $70 \%$ ) were obtained. The advantage of this strategy is that NP products were only different in hydrophobicity, while their size, shape, and core materials were controlled identical. The average core diameters of gold NPs were $7.6 \pm 0.9 \mathrm{~nm}(\mathrm{NP} 01), 6.7 \pm 1.0 \mathrm{~nm}$ (NP02), $7.5 \pm 0.9 \mathrm{~nm}$ (NP03), and $7.1 \pm 1.1 \mathrm{~nm}$ (NP04) as characterized by transmission electrical microscopy (TEM) (Figures 2A-D).

We have previously shown that $\log \mathrm{P}$ value of surface ligand did not predict LogP of NPs (Li et al., 2015) and therefore, we experimentally determined the LogP values of these NPs using "shaking flask" method. Their LogP values were ranging from -2.6 to 2.4 (Figure 2E). This range is wide enough to represent most NPs used in various applications nowadays. In aqueous solution, hydrodynamic diameters of the NP array were in a range of 150 300 $\mathrm{nm}$ (Figure 2F). Protein adsorption will help NP suspend. We observed that the hydrodynamic diameters of several NPs decreased after protein adsorption. All NPs exhibited negatively charged surface in water with zeta potential values around $-20 \mathrm{mV}$ (Figure 2G). After protein adsorption, zeta potentials did not change much. These results revealed that protein adsorption could influence the physicochemical properties of NPs in some way.

\section{Nanoparticles With Higher Hydrophobic Surface Adsorbed More Proteins}

To understand the impacts of NP hydrophobicity on the formation of protein corona, we quantitatively and qualitatively analyzed of adsorbed proteins by NPs. First, the protein corona was analyzed using SDS-PAGE after proteins were dissociated from NPs (Figure 3A). After Coomassie brilliant blue staining, many protein bands appeared, indicating that various serum proteins were adsorbed to NP surface. The molecular weight of 
A
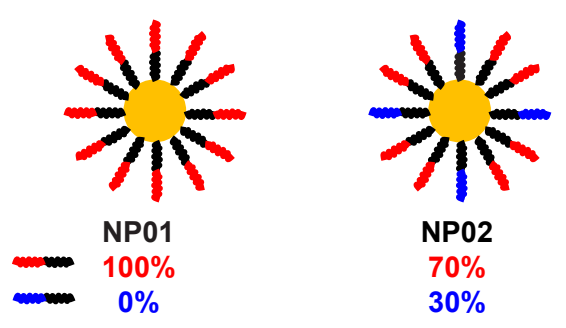
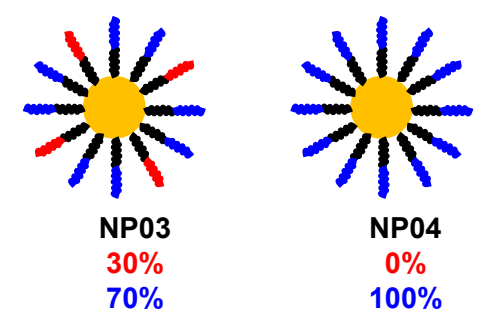

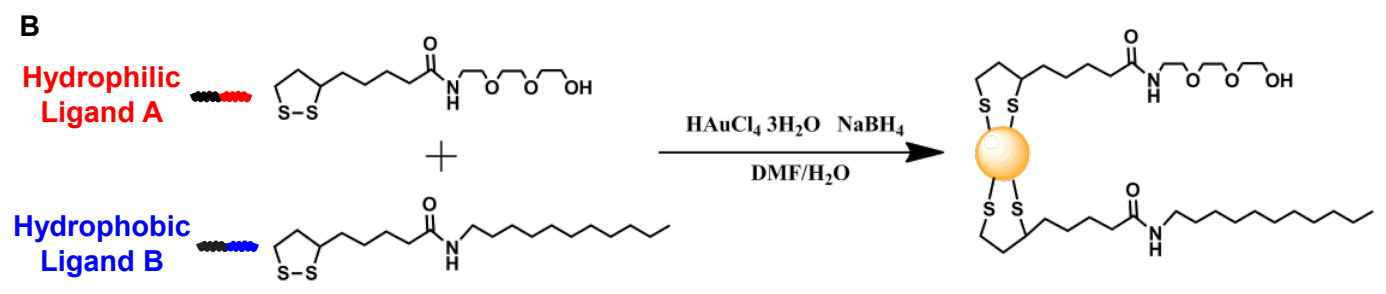

FIGURE 1 | (A) Four nanoparticles (NP01 NP04) were synthesized with continuous change in hydrophobicity. (B) Ligand chemical structures and the synthesis route.
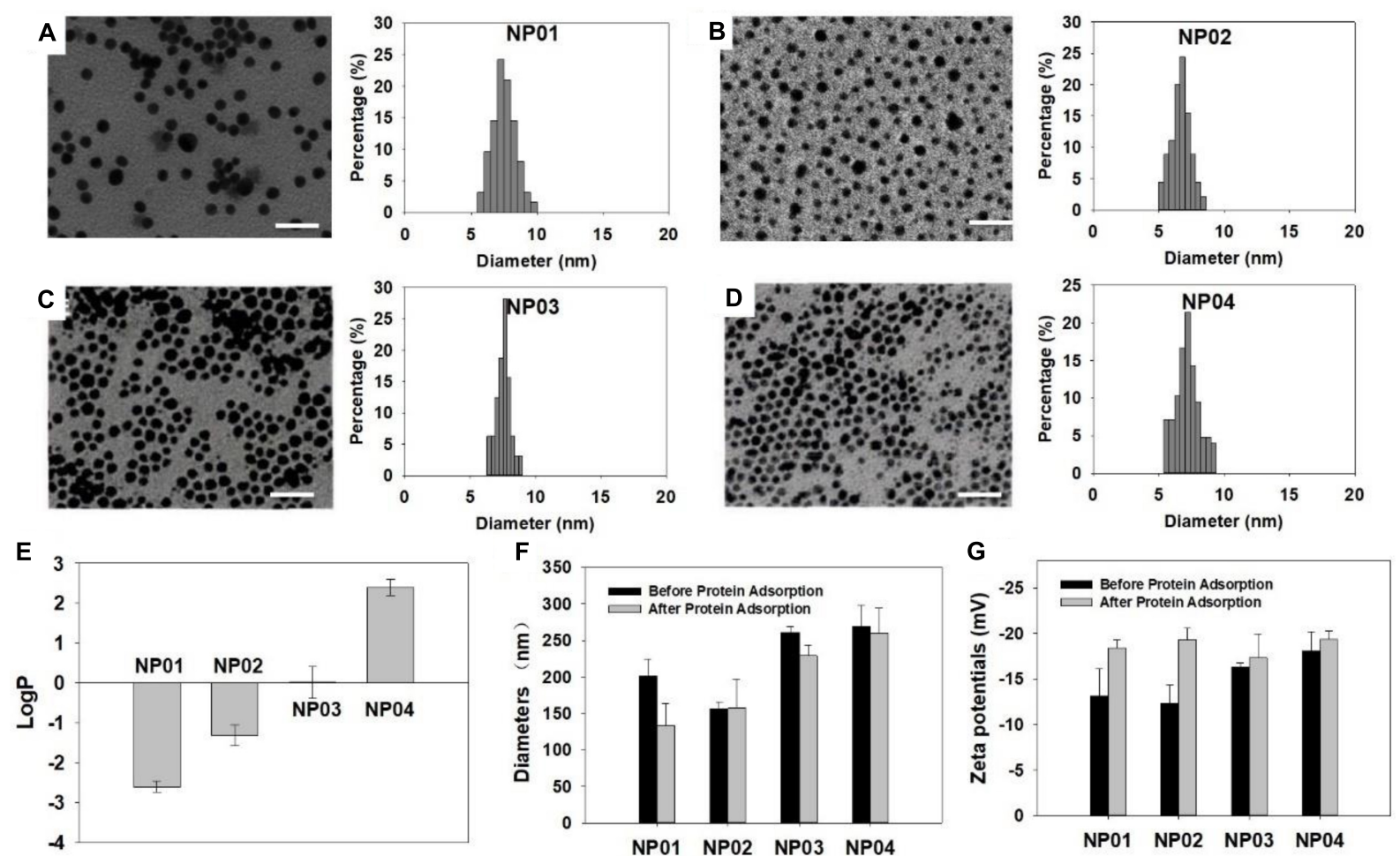

FIGURE 2 | Characterization of NPs. (A-D) TEM images and size distribution of NPs. (A) NP01, (B) NP02, (C) NP03, (D) NP04. Scale bar: 25 nm. (E) LogP values of NPs. (F) Hydrodynamic diameters and (G) zeta potentials of NPs before and after protein adsorption.

each band represented protein identity, while the intensity of each band reflected amounts of adsorbed proteins. We observed that band intensity gradual increased with the NP hydrophobicity increasing, suggesting more proteins were bound to NPs with higher hydrophobicity. In a more quantitative measurement, the isolated proteins were quantitatively analyzed by BCA assays (Figure 3B). More hydrophilic NP01 adsorbed about $12 \mu \mathrm{g}$ proteins per milligram of NPs while the amounts of adsorbed proteins increased with NP hydrophobicity to about $26 \mu \mathrm{g}$ proteins per milligram of NPs. This trend was consistent with the results of SDS-PAGE. Hydrophobic NPs with higher surface energy (Mandal et al., 2012) provides stronger hydrophobic interactions between NPs and proteins, resulted in increased protein adsorption. 
A

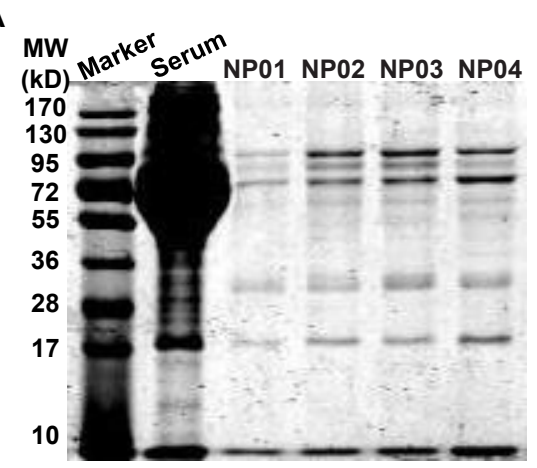

B

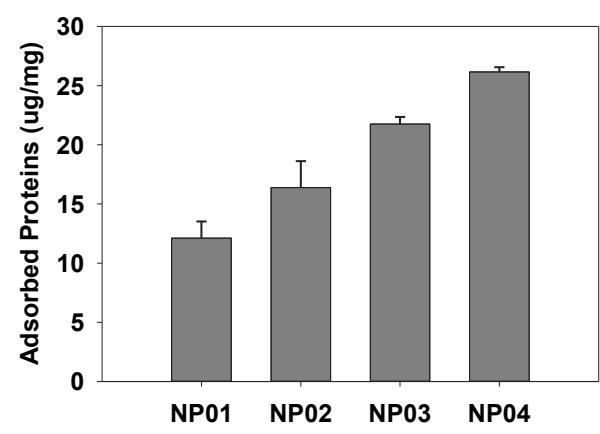

FIGURE 3 | (A) Qualitative characterization of protein corona on nanoparticles using SDS-PAGE. (B) Quantitative analysis of the amounts of adsorbed proteins by BCA assays.

\section{Small and Negatively Charged Proteins Were Preferably Adsorbed to NPs With Hydrophobic Surface}

The composition analysis of the protein corona on four NPs was analyzed using electrospray nano-liquid chromatography mass spectrometry (nano-LC-MS/MS) (Griffin et al., 2010; Eeltink et al., 2017). Identified proteins were listed in Supplementary Table S1. Total 21, 58, 82, and 41 proteins in detectable quantity were found on NP01, NP02, NP03, and NP04, respectively.

Relative abundance (RPA) of corona proteins was also determined by nano-LC-MS/MS. We first classified proteins by their molecular weights and isoelectric points. As shown in Figure 4A, NPs with different hydrophobicity were able to selectively bind different proteins according to their molecular weights. Due to large surface curvature of $7 \mathrm{~nm}$ NPs, all NPs exhibited low affinity for proteins $>100 \mathrm{kDa}$, while proteins $<100 \mathrm{kDa}$ accounted for more than $90 \%$ of the protein corona. In particular, NP02, NP03 and NP04 exhibited strong affinity for proteins with molecular weights $<50 \mathrm{kDa}$ (about 71, 70, and $73 \%$ for NP02, NP03 and NP04, respectively), while NP01 even though adsorbed maily proteins between $<100 \mathrm{KDa}(99 \%)$, it adsorbed twice as much proteins with molecular weights between 50 and $100 \mathrm{KDa}$ (about 43\%) compared to other three NPs (about 21, 24, and 26\%). Finally, the amount of proteins $<25 \mathrm{kDa}$ in the corona of NP01 was a half (about 24\%) compared to other three NPs $(41 \sim 49 \%)$. The results indicating the distribution of protein molecular weight was similar between medium hydrophobic NPs and high hydrophobic NPs, but different with hydrophilic NPs.

Further analyses were performed to understand the relationship between protein isoelectric point and protein corona. Figure $\mathbf{4 B}$ shows that the largest fraction of corona proteins has a negative charge (isoelectric point, pI $<7$ ) (about 61, 85, 82, and 79\% for NP01, NP02, NP03, and NP04, respectively). Moreover, NP01, NP02, and NP04 adsorbed mainly proteins with a pI $<6$ (about 50\% for the three NPs), while NP03 adsorbed mainly proteins with a pI between 6 and 7 (48\%). NP01 and NP04 adsorbed twofold proteins with a $\mathrm{pI}>8$ (about 20\%) compared to other two NPs. NP01 adsorbed lowest abundance of proteins with PI $6 \sim 7$ and highest abundance of proteins with PI 7 8 compared to other three NPs. PIs represent the electronic distribution of adsorbed proteins and possible electrostatic interactions between NPs and proteins. Although the conjugated ligands were neutral and zeta potentials of NPs were medium negative, proteins with negative charge in solution were more preferred binding to NPs. The stronger bindings between these proteins and NPs were possible mainly through the hydrogen bonds and hydrophobic forces for hydrophilic NPs and hydrophobic NPs, respectively.

\section{Identification of Proteins Binding to NPs With Different Hydrophobicity}

Protein composition analysis showed that top 10 bound proteins constituted about $80-90 \%$ of the total adsorbed proteins (Figure 5 and Supplementary Table S1). Particularly, for NP04, top 10 and top 5 bound proteins constituted $96 \%$ and $91 \%$ of the total protein content, respectively. The results indicated that relatively few types of proteins were enriched by NPs from thousands of serum proteins. Apolipoprotein A-I and Apolipoprotein E were adsorbed to all NPs with similar RPA. The hydrophobic forces may be not involved in the interactions between NPs and these proteins. As surface hydrophobic increasing, NPs adsorbed more hemoglobin fetal subunit beta (from $4 \%$ to $35 \%$ ) and serum albumin (from $0.3 \%$ to $23 \%$ ), indicating these proteins would prefer binding to hydrophobic surface with involvement of strong hydrophobic forces. On the other hand, the relative amounts of some proteins in the corona decreased as the surface hydrophobicity increased. Such proteins included vitronectin (decreased from $6.7 \%$ to $1.1 \%$ ), and antithrombin III (decreased from $14.3 \%$ to $0.5 \%$ ). Besides, talin 1 and prothrombin were found to prefer binding to surface with medium hydrophobicity. Interactions between NPs and proteins are complicated. Fully understanding the mechanisms of interactions between these proteins and NP surface with different hydrophobicity should consider the three-dimension structure of these proteins (Khan et al., 2013; Kharazian et al., 2016). In our further work, we will use computation modeling to investigate the related mechanisms. 
A

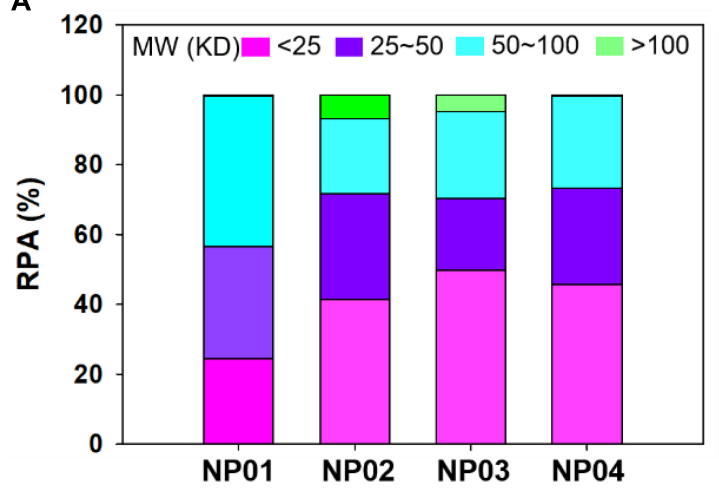

B

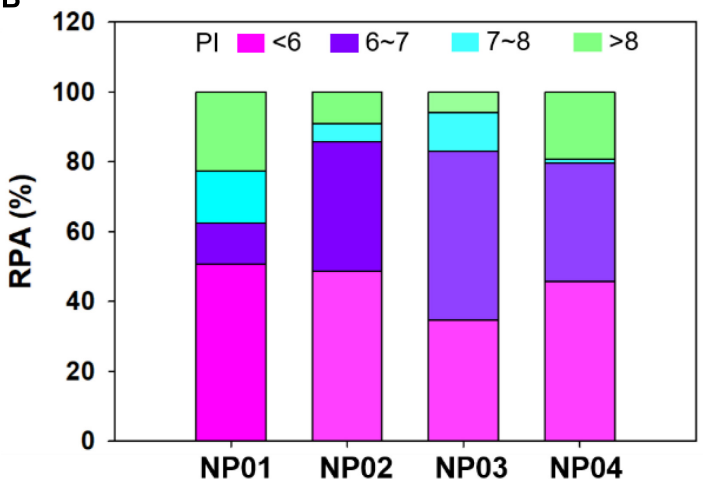

FIGURE 4 | Relative protein abundance of protein corona classified according to their molecular mass (A) and isoelectric point (B).

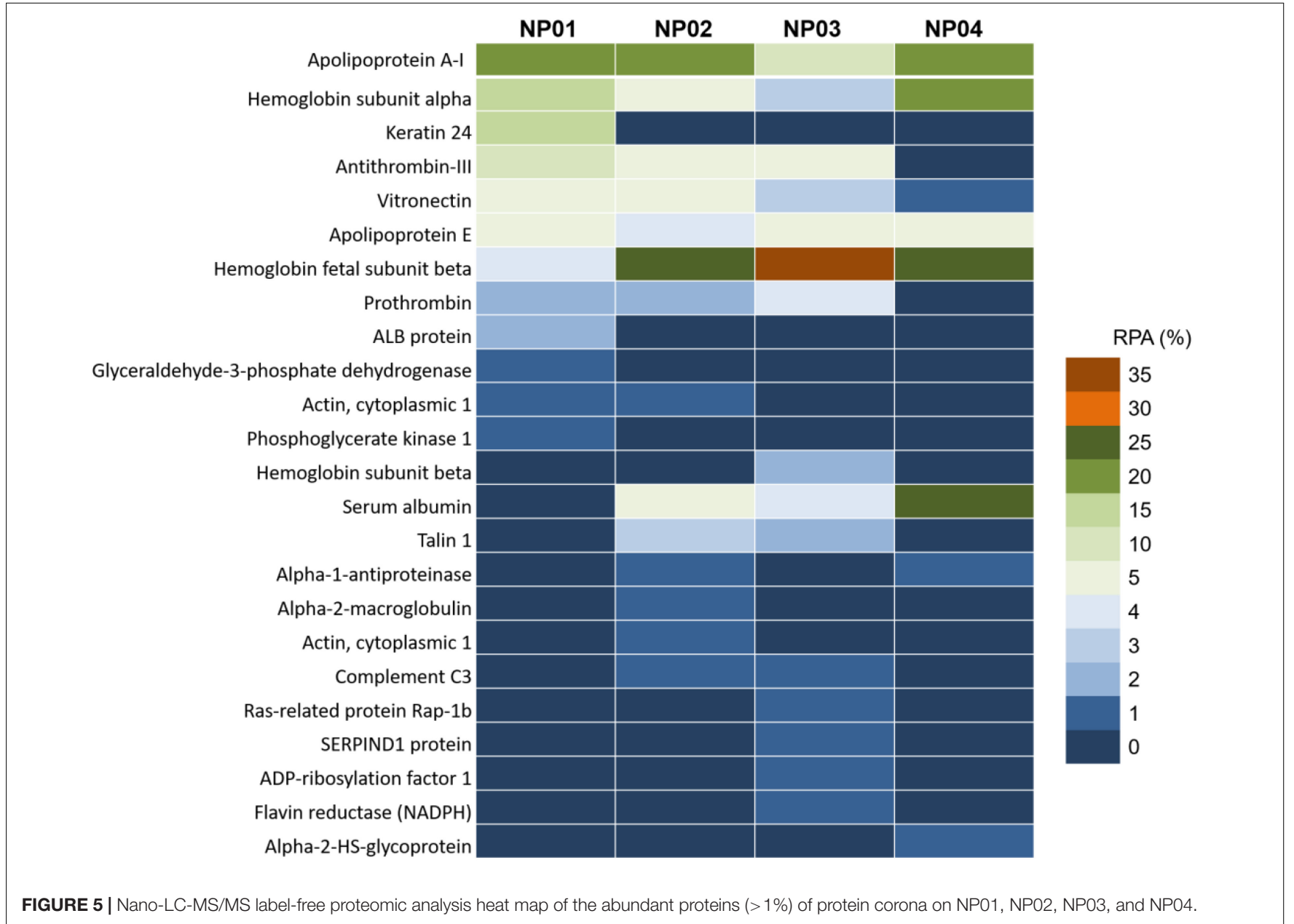

Consistent with previous reported results, the amounts of the proteins in the corona were not correlated with their relative abundance in the serum (Sakulkhu et al., 2015; Vidaurre-Agut et al., 2019). For example, serum digestion and analysis confirmed that serum albumin (about 60\% in serum) was one of the most abundant proteins found in the 10\% FBS used for these experiments, but it was found in relatively low abundance on
NP01, NP02, and NP03, constituting less than 5\% of the complete corona. Similarly, one of the most abundant serum proteins, serotransferrin (about $4 \%$ in serum), was only identified on NP03 with the RPA of $0.1 \%$. On the other hand, hemoglobin subunit alpha and hemoglobin fetal subunit beta found in trace concentrations in serum, however, was the major component of the corona of all particles. Therefore, NPs with different surface 


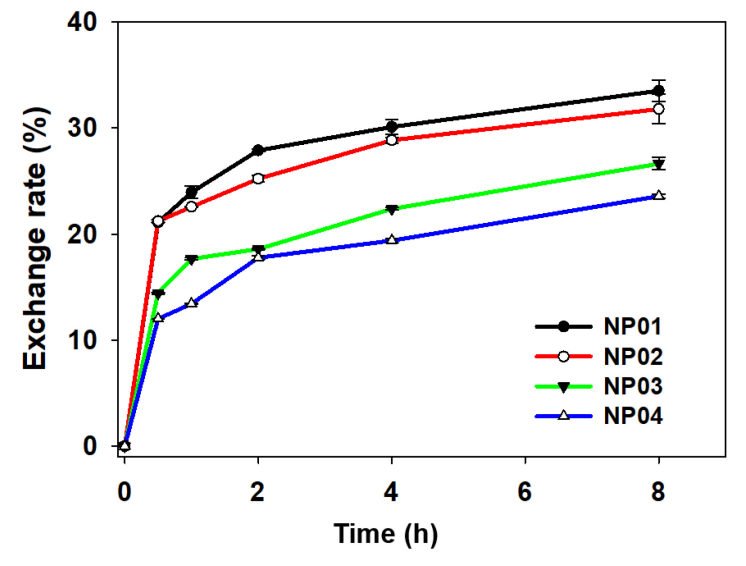

FIGURE 6 | Dynamic protein exchange between FITC-labeled BSA and non-labeled BSA.

chemistry can be used to enrich certain proteins for proteomic research (Wang et al., 2018; Yao et al., 2018).

\section{Protein Exchange Rate Was Higher on Hydrophilic NPs Than Hydrophobic NPs}

Protein corona has shown notable impact on the biological behavior of NPs in biological systems. However, a puzzling dilemma is whether hard protein corona completely shields a NP or the NP is still exposed? To test this, we designed an experiment to examine protein exchange between NPs covered with fluorescence-labeled protein corona and non-fluorescencelabeled proteins in solution. A labeled model protein, FITClabeled bovine fetal albumin (BSA), was used to form hard protein corona with NP01-NP04 in this study. When FITClabeled BSA was adsorbed to NPs, the fluorescence of FITC was partially quenched by gold NPs. Protein-covered NPs were isolated by centrifugation and washed with PBS, leaving only hard protein corona on NP01-NP04. After exchanging with nonlabeled proteins in the solution, the fluorescence of FITC in the supernatant was continuously measured. The protein exchange rates were calculated based on the fluorescence intensity. As shown in Figure 6, after $8 \mathrm{~h}$ incubation, the highest protein exchange rate happened on the surface of NP01, reached $34 \%$, while the lowest took place on NP04, was 23\%. The experimental findings demonstrated that hard corona was not binding as tightly as covalent bindings. These non-covalently bound proteins were freely exchange with counterparts in solution. Therefore, NPs are not completely shielded. Hydrophobic surface adsorbed about twofold more proteins than hydrophilic surface (see the results of BCA assays), and the dense packed adsorbed proteins restricted the exchange with free proteins in the solution.

Numerous studies have reported nano-bio interactions were correlated to NPs' original physicochemical properties, including hydrophobicity, charge, ligand structure, and core composition. For example, NPs modified with targeting moieties showed enhanced cellular internalization in protein-rich medium. The dynamic exchange behavior of adsorbed proteins told us NPs could expose themselves in physiological systems even though proteins were coated at the outmost layer. Adsorbed proteins were loosely associated with NPs and they also underwent quick and frequent exchanges with proteins in solution. Therefore, protein corona does not block the original physicochemical properties of NPs.

\section{CONCLUSION}

To study the relationships between surface hydrophobicity and the formation and dynamic behavior of the protein corona, a NP array was synthesized with a wide range of surface hydrophobicity with $\log \mathrm{P}$ values ranging from -2.6 to +2.4 . Hydrophobic NP surface adsorbed 2.1-fold proteins compared to hydrophilic ones which was attributed to the stronger hydrophobic interactions. Due to large surface curvature and electrostatic interactions, the most adsorbed proteins had small molecular weights and negatively charge, especially for hydrophobic surface. Apolipoproteins were adsorbed to all types of NPs, with no significant differences on bound amount. On the other hand, hemoglobin fetal subunit beta and serum albumin preferred binding to hydrophobic NPs, while vitronectin and antithrombin III preferred binding to hydrophilic NPs. Furthermore, hydrophilic NPs exhibited a higher hard corona protein exchange rate than the hydrophobic NPs. These findings enhanced our understanding on the control of protein adsorption and protein exchange dynamics. These understandings will help advance the design of the next generation of nanomedicines.

\section{DATA AVAILABILITY STATEMENT}

The data found in this study can be found on ProteomeXchange, accession number PXD017429.

\section{AUTHOR CONTRIBUTIONS}

BY and GS conceived this project, designed the methodology, and participated in writing the manuscript. QY synthesized the nanoparticles. QY, LZ, and CG performed the rest of the experiments. All authors have read and approved the final manuscript.

\section{FUNDING}

This work was supported by the National Key R\&D Program of China (2016YFA0203103) and the National Natural Science Foundation of China (91543204 and 91643204).

\section{SUPPLEMENTARY MATERIAL}

The Supplementary Material for this article can be found online at: https://www.frontiersin.org/articles/10.3389/fbioe.2020. 00210/full\#supplementary-material 


\section{REFERENCES}

Ashby, J., Pan, S., and Zhong, W. (2014). Size and surface functionalization of iron oxide nanoparticles influence the composition and dynamic nature of their protein corona. ACS Appl. Mater. Interfaces 6, 15412-15419. doi: 10.1021/ am503909q

Caracciolo, G., Palchetti, S., Colapicchioni, V., Digiacomo, L., Pozzi, D., Capriotti, A. L., et al. (2015). Stealth effect of biomolecular corona on nanoparticle uptake by immune cells. Langmuir 31, 10764-10773. doi: 10.1021/acs.langmuir. 5b02158

Cedervall, T., Lynch, I., Foy, M., Berggård, T., Donnelly, S. C., Cagney, G., et al. (2007a). Detailed identification of plasma proteins adsorbed on copolymer nanoparticles. Angew. Chem. Int.Ed. 46, 5754-5756. doi: 10.1002/anie. 200700465

Cedervall, T., Lynch, I., Lindman, S., Berggård, T., Thulin, E., Nilsson, H., et al. (2007b). Understanding the nanoparticle-protein corona using methods to quantify exchange rates and affinities of proteins for nanoparticles. Proc. Natl. Acad. Sci. U.S.A. 104, 2050-2055. doi: 10.1073/pnas.0608582104

Clemments, A. M., Botella, P., and Landry, C. C. (2015). Protein adsorption from biofluids on silica nanoparticles: corona analysis as a function of particle diameter and porosity. ACS Appl. Mater.Interfaces 7, 21682-21689. doi: 10. 1021/acsami.5b07631

Cunningham, A. J., Robinson, M., Banquy, X., Leblond, J., and Zhu, X. (2018). Bile acid-based drug delivery systems for enhanced doxorubicin encapsulation: comparing hydrophobic and ionic interactions in drug loading and release. $\mathrm{Mol}$. Pharm. 15, 1266-1276. doi: 10.1021/acs.molpharmaceut.7b01091

Eeltink, S., Wouters, S., Dores-Sousa, J. L., and Svec, F. (2017). Advances in organic polymer-based monolithic column technology for high-resolution liquid chromatography-mass spectrometry profiling of antibodies, intact proteins, oligonucleotides, and peptides. J. Chromatogr. A 1498, 8-21. doi: 10.1016/j. chroma.2017.01.002

Gebauer, J. S., Malissek, M., Simon, S., Knauer, S. K., Maskos, M., Stauber, R. H., et al. (2012). Impact of the nanoparticle-protein corona on colloidal stability and protein structure. Langmuir 28, 9673-9679. doi: 10.1021/la301104a

Glancy, D., Zhang, Y., Wu, J. L., Ouyang, B., Ohta, S., and Chan, W. C. (2019). Characterizing the protein corona of sub-10 nm nanoparticles. J. Control. Release 304, 102-110. doi: 10.1016/j.jconrel.2019.04.023

Griffin, N. M., Yu, J., Long, F., Oh, P., Shore, S., Li, Y., et al. (2010). Label-free, normalized quantification of complex mass spectrometry data for proteomic analysis. Nat. Biotechnol. 28, 83. doi: 10.1038/nbt.1592

Johnston, B. D., Kreyling, W. G., Pfeiffer, C., Schäffler, M., Sarioglu, H., Ristig, S., et al. (2017). Colloidal stability and surface chemistry are key factors for the composition of the protein corona of inorganic gold nanoparticles. Adv. Funct. Mater. 27:1701956. doi: 10.1002/adfm.201701956

Ke, P. C., Lin, S., Parak, W. J., Davis, T. P., and Caruso, F. (2017). A decade of the protein corona. ACS Nano 11, 11773-11776. doi: 10.1021/acsnano.7b08008

Ke, Y., Castro, C., and Choi, J. H. (2018). Structural DNA nanotechnology: artificial nanostructures for biomedical research. Annu. Rev. Biomed. Eng. 20, 375-401. doi: 10.1146/annurev-bioeng-062117-120904

Khan, S., Gupta, A., and Nandi, C. K. (2013). Controlling the fate of protein corona by tuning surface properties of nanoparticles. J. Phys.Chemi.Lett. 4, 3747-3752. doi: $10.1021 / \mathrm{jz} 401874 \mathrm{u}$

Kharazian, B., Hadipour, N., and Ejtehadi, M. (2016). Understanding the nanoparticle-protein corona complexes using computational and experimental methods. Int. J. Biochem.Cell Biol. 75, 162-174. doi: 10.1016/j.biocel.2016. 02.008

Lesniak, A., Fenaroli, F., Monopoli, M. P., Åberg, C., Dawson, K. A., and Salvati, A. (2012). Effects of the presence or absence of a protein corona on silica nanoparticle uptake and impact on cells. ACS Nano 6, 5845-5857. doi: 10.1021/ nn300223w

Li, S., Zhai, S., Liu, Y., Zhou, H., Wu, J., Jiao, Q., et al. (2015). Experimental modulation and computational model of nano-hydrophobicity. Biomaterials 52, 312-317. doi: 10.1016/j.biomaterials.2015.02.043

Liu, X., and Dai, L. (2016). Carbon-based metal-free catalysts. Nat .Rev. Mater. 1:16064. doi: 10.1038 /natrevmats.2016.64

Liu, Y., Pharr, M., and Salvatore, G. A. (2017). Lab-on-skin: a review of flexible and stretchable electronics for wearable health monitoring. ACS Nano 11, 9614-9635. doi: 10.1021/acsnano.7b04898
Lundqvist, M., Stigler, J., Elia, G., Lynch, I., Cedervall, T., and Dawson, K. A. (2008). Nanoparticle size and surface properties determine the protein corona with possible implications for biological impacts. Proc. Natl. Acad. Sci. U.S.A. 105, 14265-14270. doi: 10.1073/pnas.0805135105

Mahmoudi, M., Lynch, I., Ejtehadi, M. R., Monopoli, M. P., Bombelli, F. B., and Laurent, S. (2011). Protein- nanoparticle interactions: opportunities and challenges. Chemi. Rev. 111, 5610-5637. doi: 10.1021/cr100440g

Mandal, S., Ghatak, C., Rao, V. G., Ghosh, S., and Sarkar, N. (2012). Pluronic micellar aggregates loaded with gold nanoparticles (Au NPs) and fluorescent dyes: a study of controlled nanometal surface energy transfer. J.Phys.Chem. C 116, 5585-5597. doi: 10.1021/jp2093127

Marichal, L., Giraudon-Colas, G. L., Cousin, F., Thill, A., Labarre, J., Boulard, Y., et al. (2019). Protein-nanoparticle interactions: what are the protein-corona thickness and organization? Langmuir 35, 10831-10837. doi: 10.1021/acs. langmuir.9b01373

Monopoli, M. P., Walczyk, D., Campbell, A., Elia, G., Lynch, I., Baldelli Bombelli, F., et al. (2011). Physical- chemical aspects of protein corona: relevance to in vitro and in vivo biological impacts of nanoparticles. J. Am. Chem. Soc. 133, 2525-2534. doi: 10.1021/ja107583h

Nel, A. E., Mädler, L., Velegol, D., Xia, T., Hoek, E. M., Somasundaran, P., et al. (2009). Understanding biophysicochemical interactions at the nano-bio interface. Nat. Mater. 8:543. doi: 10.1038/nmat2442

Nienhaus, K., and Nienhaus, G. U. (2019). Towards a molecular-level understanding of the protein corona around nanoparticles-recent advances and persisting challenges. Curr. Opin. Biomed. Eng. 10, 11-22. doi: 10.1016/j.cobme. 2019.01.002

Pareek, V., Bhargava, A., Bhanot, V., Gupta, R., Jain, N., and Panwar, J. (2018). Formation and characterization of protein corona around nanoparticles: a review. J. Nanosci. Nanotechnol. 18, 6653-6670. doi: 10.1166/jnn.2018.15766

Ramos, A. P., Cruz, M. A., Tovani, C. B., and Ciancaglini, P. (2017). Biomedical applications of nanotechnology. Biophys. Rev. 9, 79-89. doi: 10.1007/s12551016-0246-2

Sakulkhu, U., Mahmoudi, M., Maurizi, L., Coullerez, G., Hofmann-Amtenbrink, M., Vries, M., et al. (2015). Significance of surface charge and shell material of superparamagnetic iron oxide nanoparticle (SPION) based core/shell nanoparticles on the composition of the protein corona. Biomater. Sci. 3 , 265-278. doi: 10.1039/c4bm00264d

Schöttler, S., Becker, G., Winzen, S., Steinbach, T., Mohr, K., Landfester, K., et al. (2016). Protein adsorption is required for stealth effect of poly (ethylene glycol)and poly (phosphoester)-coated nanocarriers. Nat. Nanotechnol. 11:372. doi: 10.1038/nnano.2015.330

Sharma, N., Ojha, H., Bharadwaj, A., Pathak, D. P., and Sharma, R. K. (2015). Preparation and catalytic applications of nanomaterials: a review. RSC $A d v .5$, 53381-53403. doi: 10.1039/C5RA06778B

Shemetov, A. A., Nabiev, I., and Sukhanova, A. (2012). Molecular interaction of proteins and peptides with nanoparticles. ACS Nano 6, 4585-4602. doi: 10.1021/ nn300415x

Srivastava, V., Gusain, D., and Sharma, Y. C. (2015). Critical review on the toxicity of some widely used engineered nanoparticles. Indus. Eng. Chem. Res. 54, 6209-6233. doi: 10.1021/acs.iecr.5b01610

Su, G., Jiang, H., Xu, B., Yu, Y., and Chen, X. (2018). Effects of protein corona on active and passive targeting of cyclic RGD peptide-functionalized PEGylation nanoparticles. Mol. Pharm. 15, 5019-5030. doi: 10.1021/acs.molpharmaceut. 8 b00612

Su, G., Zhou, H., Mu, Q., Zhang, Y., Li, L., Jiao, P., et al. (2012). Effective surface charge density determines the electrostatic attraction between nanoparticles and cells. J.Phys.Chem. C 116, 4993-4998. doi: 10.1021/jp211041m

Su, G., Zhou, X., Zhou, H., Li, Y., Zhang, X., Liu, Y., et al. (2016). Size-dependent facilitation of cancer cell targeting by proteins adsorbed on nanoparticles. ACS Appl. Mater. Interfaces 8, 30037-30047. doi: 10.1021/acsami.6b10967

Tenzer, S., Docter, D., Kuharev, J., Musyanovych, A., Fetz, V., Hecht, R., et al. (2013). Rapid formation of plasma protein corona critically affects nanoparticle pathophysiology. Nat. Nanotechnol. 8:772. doi: 10.1038/nnano.2013.181

Vasti, C., Bedoya, D. A., Rojas, R., and Giacomelli, C. E. (2016). Effect of the protein corona on the colloidal stability and reactivity of LDH-based nanocarriers. J. Mater. Chem.B 4, 2008-2016. doi: 10.1039/C5TB02698A

Vidaurre-Agut, C., Rivero-Buceta, E., Romaní-Cubells, E., Clemments, A. M., Vera-Donoso, C. S. D., Landry, C. C., et al. (2019). Protein corona over 
mesoporous silica nanoparticles: influence of the pore diameter on competitive adsorption and application to prostate cancer diagnostics. ACS Omega 4, 8852-8861. doi: 10.1021/acsomega.9b00460

Walkey, C. D., Olsen, J. B., Guo, H., Emili, A., and Chan, W. C. (2012). Nanoparticle size and surface chemistry determine serum protein adsorption and macrophage uptake. J. Am. Chem. Soc. 134, 2139-2147. doi: 10.1021/ ja2084338

Walkey, C. D., Olsen, J. B., Song, F., Liu, R., Guo, H., Olsen, D. W. H., et al. (2014). Protein corona fingerprinting predicts the cellular interaction of gold and silver nanoparticles. ACS Nano 8, 2439-2455. doi: 10.1021/nn406018q

Wang, M., Gustafsson, O. J., Pilkington, E. H., Kakinen, A., Javed, I., Faridi, A., et al. (2018). Nanoparticle-proteome in vitro and in vivo. J. Mater.Chem.B 6, 6026-6041. doi: 10.1039/c8tb01634h

Wei, Y., and Yan, B. (2016). Nano products in daily life: to know what we do not know. Natl.Sci. Rev. 3, 414-415. doi: 10.1093/nsr/nww073

$\mathrm{Wu}, \mathrm{W}$. (2017). Inorganic nanomaterials for printed electronics: a review. Nanoscale 9, 7342-7372. doi: 10.1039/c7nr01604b

Yahyaei, M., Mehrnejad, F., Naderi-Manesh, H., and Rezayan, A. H. (2018). Protein adsorption onto polysaccharides: comparison of chitosan and chitin polymers. Carbohydr. Polyme. 191, 191-197. doi: 10.1016/j.carbpol.2018. 03.034

Yao, J., Sun, N., and Deng, C. (2018). Recent advances in mesoporous materials for sample preparation in proteomics research. TrAC Trends Anal.Chem. 99, 88-100. doi: 10.1016/j.trac.2017.11.016

Zhong, R., Liu, Y., Zhang, P., Liu, J., Zhao, G., and Zhang, F. (2014). Discrete nanoparticle-BSA conjugates manipulated by hydrophobic interaction. ACS Appl.Mater.Interfaces 6, 19465-19470. doi: 10.1021/am506497s

Conflict of Interest: The authors declare that the research was conducted in the absence of any commercial or financial relationships that could be construed as a potential conflict of interest.

Copyright (c) $2020 \mathrm{Yu}$, Zhao, Guo, Yan and Su. This is an open-access article distributed under the terms of the Creative Commons Attribution License (CC BY). The use, distribution or reproduction in other forums is permitted, provided the original author(s) and the copyright owner(s) are credited and that the original publication in this journal is cited, in accordance with accepted academic practice. No use, distribution or reproduction is permitted which does not comply with these terms. 